\title{
History of African women in neurosurgery
}

\author{
Claire Karekezi, MD, ${ }^{1}$ Nqobile Thango, MD, ${ }^{2}$ Salamat Ahuoiza Aliu-Ibrahim, MD, ${ }^{3}$ \\ Hajar Bechri, MD, ${ }^{4}$ Espérance Maman You Broalet, MD, ${ }^{5}$ Mouna Bougrine, MD, ${ }^{6}$ \\ Jebet Beverly Cheserem, MD, ${ }^{7}$ Maguette Mbaye, MD, ${ }^{8}$ Zarina Ali Shabhay, MD, ${ }^{9}$ \\ Nabila Tighilt, MD, ${ }^{10}$ Souad Bakhti, MD, ${ }^{10}$ and Najia El Abbadi, MD ${ }^{6}$
}

\begin{abstract}
${ }^{1}$ Neurosurgery Unit, Department of Surgery, Rwanda Military Hospital, Kigali, Rwanda; ${ }^{2}$ Department of Surgery, University of Cape Town, South Africa; ${ }^{3}$ Division of Neurosurgery, Department of Surgery, University of llorin Teaching Hospital, Ilorin, Nigeria; ${ }^{4}$ Neurosurgery Department, ONO Hospital, Ibn Sina University Hospital Center, Education, Rabat Medical School, Mohammed Vth University Souissi, Rabat, Morocco; ${ }^{5}$ Department of Neurosurgery, St. Joseph Moscati Catholic Hospital, Yamoussoukro, Ivory Coast; ${ }^{6}$ Department of Neurosurgery, Cheikh Zaid International University Hospital, Abulcasis International University of Health Sciences, Rabat, Morocco; ${ }^{7}$ Department of Surgery, Aga Khan University Hospital, Nairobi, Kenya; ${ }^{8}$ Division of Neurosurgery, Department of Neurosurgery, Fann Teaching Hospital, Dakar, Senegal; ${ }^{9}$ Neurosurgery Department, Muhimbili Orthopedic Institute, Dar es Salaam, Tanzania; and ${ }^{10}$ Department of Neurosurgery, Ali Ait Idir Specialized Hospital, Algiers, Algeria
\end{abstract}

The number of women in the medical field has increased in Africa over the last few decades, yet the underrepresentation of women within neurosurgery has been a recurrent theme. Of all surgical disciplines, neurosurgery is among the least equitable, and the rate of increase in female surgeons lags behind other surgical disciplines such as general surgery. This historical review provides an overview of the history of women in neurosurgery and their current status on the African continent. To the authors' knowledge, this is the first article to provide such an overview.

https://thejns.org/doi/abs/10.3171/2020.12.FOCUS20905

KEYWORDS women in neurosurgery; Africa; history; pioneers; gender; representation

I $\mathrm{N}$ most countries the number of women within the neurosurgical field is still low. ${ }^{1}$ There is currently a paucity of data available on the exact number of women in neurosurgery (WIN) within the African continent. Irrespective of gender, the literature demonstrates that the overall number of neurosurgeons within Africa is low when compared to global figures, with some countries still without a practicing neurosurgeon..$^{2,3}$

According to our internal survey, the estimated total number of African women in neurosurgery (AWIN) is roughly 243 (female residents/trainees excluded). Northern Africa accounts for 187, which is approximately $77 \%$ of all AWIN. Further breaking the regions' figures down into countries, Algeria records the highest number and leads with more than half of the continent's WIN $(n=135)$. Morocco follows with 25, Tunisia with 12, and Sudan with 12 WIN. Egypt has the highest number of male neurosurgeons (> 500) and yet with only 3 WIN, it falls among the lowest percentages on the continent.

On the other side of the continent, within Southern Africa, the Republic of South Africa (RSA) has the highest number of registered female neurosurgeons, the total being 18, and is ranked third on the continent after Algeria and Morocco. The rest of Africa is still underrepresented, with some countries without a single practicing neurosurgeon, male or female. It is encouraging to see that numbers are rising; Western Africa currently accounts for a total of 14 WIN, and Central Africa and Eastern Africa have 8 and 15 , respectively.

In this historical review, we provide an overview of the history and current status of women neurosurgeons on the African continent.

\section{Methods}

The study is an audit based on statistics from the AWIN database along with efforts to communicate and verify numbers within the continent. Following the efforts, in this paper we aim to report the current status quo of AWIN on our continent. We further explore their representation within clinical and academic positions along with the challenges they may encounter within their everyday practice.

ABBREVIATIONS AWIN = African women in neurosurgery; CAANS = Continental Association of African Neurosurgical Societies; $D R C=$ Democratic Republic of the Congo; HOD = head of department; RSA = Republic of South Africa; WFNS = World Federation of Neurosurgical Societies; WIN = women in neurosurgery; YNF = Young Neurosurgeons Forum. 


\section{History of African Women Neurosurgeons per Region Northern Africa}

The Northern African region includes 6 countries: Algeria, Morocco, Egypt, Tunisia, Libya, and Sudan. This region counts 187 female certified neurosurgeons, making up $77 \%$ of all AWIN (Table 1).

Algeria is leading by a wide margin with 135 WIN. One of the factors that may contribute to this is that the history of WIN in Africa began in Algeria with Professor Faiza Lalam in 1977. She worked as a certified neurosurgeon in 1982 at the surgical department of Tizi Ouzou's University Hospital. In 2011, she became professor and head of department (HOD). In 2014, Professor Souad Bakhti became the first woman president of a national neurosurgical society in Africa when she became president of the Algerian Society of Neurosurgery (SANC). In 2017, she was appointed as HOD in neurosurgery at the Specialized Hospital Ali Ait Idir in Algiers. At a continental level, she was the only female neurosurgeon present during the creation of the Continental Association of African Neurosurgical Societies (CAANS) in Cape Town in 2012, where she served as treasurer and second vice president for North Africa. She is currently chair of the World Federation of Neurosurgical Societies (WFNS) Women in Neurosurgery Committee 4 and secretary of the Pan Arab Neurosurgical Society (PANS). Dr. Nabila Tighilt holds a leadership position as the current first vice president of the Algerian Society of Neurosurgery. Algeria has the highest rate of certified WIN (Fig. 1), representing 33\% of all Algerian neurosurgeons and $56 \%$ of all AWIN, with a rate of $55 \%$ of female neurosurgical residents. This was possible because Algeria advocated for education for both genders. This has led to women identifying mentors early in life, and entry into a specialty training like neurosurgery is based purely on academic merit.

Morocco, with 25 female neurosurgeons, ranks as the African country with the second highest number of female neurosurgeons. Professor Najia El Abbadi was the first practicing female neurosurgeon at Ibn Sina Hospital in Rabat. She trained as a fellow in several departments all around the world and became the first African female professor of neurosurgery in 1994. She was nominated as head of the neurosurgical department at Ibn Sina Hospital from 2014 to 2016, then moved to Cheikh Zaid International University Hospital, where she holds the position of HOD in neurosurgery, along with being chair of the Department of Surgery at Abulcasis International University of Health Sciences. She was elected the first female president of the Moroccan Society of Neurosurgery (SMNC) in 2015 and became the first African chair of the WFNS Women in Neurosurgery Committee from 2013 to 2017. ${ }^{4}$ In this position she was able to highlight the social difficulties of African female neurosurgeons around the world. She also served as treasurer of the CAANS in 2016 and has been assistant treasurer of the WFNS from 2018 to date. In 2018, she became the first female president of the Pan Arab Neurosurgical Society. Dr. Mouna Bougrine holds a leadership position as the secretary of the Moroccan Society of Neurosurgery.

Tunisia counts, to the best of our knowledge, 12 certified neurosurgeons. Dr. Faten Abid was the first female neurosurgeon in the country. She graduated from Monastir's medical school and trained in Monastir and at Pitié-Salpêtrière University Hospital in Paris. She is now practicing as a neurosurgeon in the Hospital Fattouma Bourguiba in Monastir. Tunisia has only 2 associate female professors of neurosurgery and no full professor.

Sudan counts 12 women neurosurgeons with 13 female residents and has done an incredible job in increasing its female representation. Egypt is one of the African countries that has one of the lowest rates of WIN (1.2\%) within the region, and contrasts that by having the highest number of male neurosurgeons, exceeding 500. Dr. Djamila Kafoufi Benderbous is the first certified female neurosurgeon in Egypt. She trained as a neurosurgeon in Algeria, then joined the Neurosurgery Department of Necker Hospital in Paris, and then in Egypt. Egypt counts only 3 WIN with 10 female residents.

\section{Western Africa}

Nigeria. Neurosurgery in West Africa started in October 1962, after Dr. E. Latunde Odeku became the first neurosurgeon in West Africa when he relocated to the University of Ibadan, Nigeria., ${ }^{5,6}$ It took another 52 years before Nigeria had its first female neurosurgeon: Dr. Salamat Ahuoiza Aliu-Ibrahim, who was admitted as a fellow in neurosurgey of the West African College of Surgeons in 2015. Dr. Salamat Ahuoiza Aliu-Ibrahim completed her residency training at the National Hospital in Abuja. She then continued her training by pursuing a fellowship in pediatric neurosurgery at Boston Children's Hospital, which she completed in 2019. She is currently practicing at the University of Ilorin Teaching Hospital in Nigeria. As a pioneer she set the path for female neurosurgeons in Nigeria-to date another 4 women have qualified, 3 of whom hold academic positions as faculty in teaching hospitals in the country. There are 2 women who are currently enrolled in the residency program. Nigeria has 80 registered neurosurgeons at last count, and only 5 (6.2\%) are female.

Ivory Coast. In 2006, Dr. Espérance Maman You Broalet became the first woman in neurosurgery in West Africa when she graduated from Abidjan. She then practiced at the Yopougon CHU in Abidjan until 2015, after which she relocated to the Université de Bouaké in the center of Ivory Coast, $350 \mathrm{~km}$ from Abidjan. In October 2019 she transferred to the St. Joseph Moscati Catholic Hospital in Yamoussoukro, where she was assigned the important task of setting up a neurosurgical department, where she is currently the HOD. Dr. Broalet is an academic and leader within the field of neurosurgery; her accolades include being the first female associate lecturer in anatomy and neurosurgery at the African and Malagasy Council for Higher Education (CAMES). In 2013 she founded "Espérance's Hope," which is an Ivorian association that aims to combat hydrocephalus and neural tube defects in the region. She has served as treasurer of the Ivorian Society of Neurosurgery (SINC) in 2017 and 2019.

Ivory Coast currently has 5 female residents from Ivory Coast and Cameroon who are enrolled in various neurosurgical training programs across the country.

Senegal. Senegal has trained the highest number of fe- 
TABLE 1. Distribution of female neurosurgeons in individual African countries, number of academic professors and associate professors

\begin{tabular}{|c|c|c|c|c|c|c|}
\hline \multirow[b]{3}{*}{ Country } & \multicolumn{6}{|c|}{ African Female Neurosurgeons } \\
\hline & \multicolumn{2}{|c|}{ All African Female Neurosurgeons } & \multicolumn{2}{|c|}{ No. at Academic Level* } & \multicolumn{2}{|c|}{$\%$ at Academic Level $\dagger$} \\
\hline & Frequency & $\%$ & Full Professors & Associate Professors & $\%$ Full Professors & $\%$ Associate Professors \\
\hline Northern Africa & \multicolumn{2}{|c|}{$187(77 \%)$} & & & & \\
\hline Algeria & 135 & 55.6 & 5 & 5 & 2 & 2 \\
\hline Egypt & 3 & 1.2 & 0 & 0 & 0 & 0 \\
\hline Libya & 0 & 0 & 0 & 0 & 0 & 0 \\
\hline Morocco & 25 & 10.3 & 3 & 1 & 1.2 & 0.4 \\
\hline Sudan & 12 & 4.9 & 0 & 0 & 0 & 0 \\
\hline Tunisia & 12 & 4.9 & 0 & 2 & 0 & 0.8 \\
\hline Eastern Africa & \multicolumn{2}{|c|}{$15(6.2 \%)$} & & & & \\
\hline Burundi & 0 & 0 & 0 & 0 & 0 & 0 \\
\hline Comoros & 0 & 0 & 0 & 0 & 0 & 0 \\
\hline Djibouti & 0 & 0 & 0 & 0 & 0 & 0 \\
\hline Eritrea & 0 & 0 & 0 & 0 & 0 & 0 \\
\hline Ethiopia & 2 & 0.8 & 0 & 0 & 0 & 0 \\
\hline Kenya & 6 & 2.5 & 0 & 0 & 0 & 0 \\
\hline Madagascar & 1 & 0.4 & 0 & 0 & 0 & 0 \\
\hline Malawi & 0 & 0 & 0 & 0 & 0 & 0 \\
\hline Mauritius & 0 & 0 & 0 & 0 & 0 & 0 \\
\hline Rwanda & 1 & 0.4 & 0 & 0 & 0 & 0 \\
\hline Seychelles & 0 & 0 & 0 & 0 & 0 & 0 \\
\hline Somalia & 0 & 0 & 0 & 0 & 0 & 0 \\
\hline South Sudan & 0 & 0 & 0 & 0 & 0 & 0 \\
\hline Tanzania & 4 & 1.7 & 0 & 0 & 0 & 0 \\
\hline Uganda & 1 & 0.4 & 0 & 0 & 0 & 0 \\
\hline Western Africa & \multicolumn{2}{|c|}{$14(5.7 \%)$} & & & & \\
\hline Benin & 0 & 0 & 0 & 0 & 0 & 0 \\
\hline Burkina Faso & 0 & 0 & 0 & 0 & 0 & 0 \\
\hline Cape Verde & 1 & 0.4 & 0 & 0 & 0 & 0 \\
\hline Gambia & 1 & 0.4 & 0 & 0 & 0 & 0 \\
\hline Ghana & 0 & 0 & 0 & 0 & 0 & 0 \\
\hline Guinea & 1 & 0.4 & 0 & 0 & 0 & 0 \\
\hline Guinea-Bissau & 0 & 0 & 0 & 0 & 0 & 0 \\
\hline Ivory Coast & 1 & 0.4 & 0 & 1 & 0 & 0.4 \\
\hline Liberia & 0 & 0 & 0 & 0 & 0 & 0 \\
\hline Mali & 0 & 0 & 0 & 0 & 0 & 0 \\
\hline Mauritania & 0 & 0 & 0 & 0 & 0 & 0 \\
\hline Niger & 1 & 0.4 & 0 & 1 & 0 & 0.4 \\
\hline Nigeria & 5 & 2 & 0 & 0 & 0 & 0 \\
\hline Senegal & 4 & 1.7 & 0 & 2 & 0 & 0.8 \\
\hline Sierra Leone & 0 & 0 & 0 & 0 & 0 & 0 \\
\hline Togo & 0 & 0 & 0 & 0 & 0 & 0 \\
\hline Central Africa & & & & & & \\
\hline Angola & 0 & 0 & 0 & 0 & 0 & 0 \\
\hline Cameroon & 5 & 2 & 0 & 0 & 0 & 0 \\
\hline Central Africa Republic & 0 & 0 & 0 & 0 & 0 & 0 \\
\hline Chad & 0 & 0 & 0 & 0 & 0 & 0 \\
\hline DRC & 1 & 0.4 & 0 & 0 & 0 & 0 \\
\hline
\end{tabular}


TABLE 1. Distribution of female neurosurgeons in individual African countries, number of academic professors and associate professors

\begin{tabular}{|c|c|c|c|c|c|c|}
\hline \multirow[b]{3}{*}{ Country } & \multicolumn{6}{|c|}{ African Female Neurosurgeons } \\
\hline & \multicolumn{2}{|c|}{ All African Female Neurosurgeons } & \multicolumn{2}{|c|}{ No. at Academic Level ${ }^{*}$} & \multicolumn{2}{|c|}{$\%$ at Academic Level $\dagger$} \\
\hline & Frequency & $\%$ & Full Professors & Associate Professors & $\%$ Full Professors & $\%$ Associate Professors \\
\hline \multicolumn{7}{|l|}{ Central Africa (continued) } \\
\hline Equatorial Guinea & 0 & 0 & 0 & 0 & 0 & 0 \\
\hline Gabon & 2 & 0.8 & 0 & 0 & 0 & 0 \\
\hline Republic of Congo & 0 & 0 & 0 & 0 & 0 & 0 \\
\hline São Tomé and Príncipe & 0 & 0 & 0 & 0 & 0 & 0 \\
\hline Southern Africa & \multicolumn{2}{|c|}{$19(7.8 \%)$} & & & & \\
\hline Botswana & 0 & 0 & 0 & 0 & 0 & 0 \\
\hline Lesotho & 0 & 0 & 0 & 0 & 0 & 0 \\
\hline Mozambique & 0 & 0 & 0 & 0 & 0 & 0 \\
\hline Namibia & 0 & 0 & 0 & 0 & 0 & 0 \\
\hline RSA & 18 & 7.4 & 0 & 0 & 0 & 0 \\
\hline Swaziland & 0 & 0 & 0 & 0 & 0 & 0 \\
\hline Zambia & 0 & 0 & 0 & 0 & 0 & 0 \\
\hline Zimbabwe & 1 & 0.4 & 0 & 0 & 0 & 0 \\
\hline Total & 243 & 100 & 8 & 12 & 3.2 & 4.9 \\
\hline
\end{tabular}

* Total number based on WIN database. Full professorship is defined as a senior-level professor with a PhD or via an ad hominem promotion process.

† Percentage is calculated according to total number of African female neurosurgeons $(\mathrm{N}=243)$ as of November 2020.

male neurosurgeons within the West African region-since 1997 a total of 10 women qualified from within not only Senegal but also Cameroon, Gabon, Democratic Republic of the Congo (DRC), and Niger. To date, Senegal counts 4 female Senegalese certified neurosurgeons, and 13 of 37 neurosurgical trainees are women. They set an example that other countries can aspire to. This is a true representa- tion of how a secure pipeline in mentorship can increase female representation within a specialty. Dr. Mame Salimata Diene became a pioneer as the first woman in neurosurgery. Currently, she is the assistant head of clinic in the Neurosurgery Department of Fann Teaching Hospital. Following her, Dr. Magatte Gaye Sakho started her training in neurosurgery in 2002. After 4 years of training in Dakar,

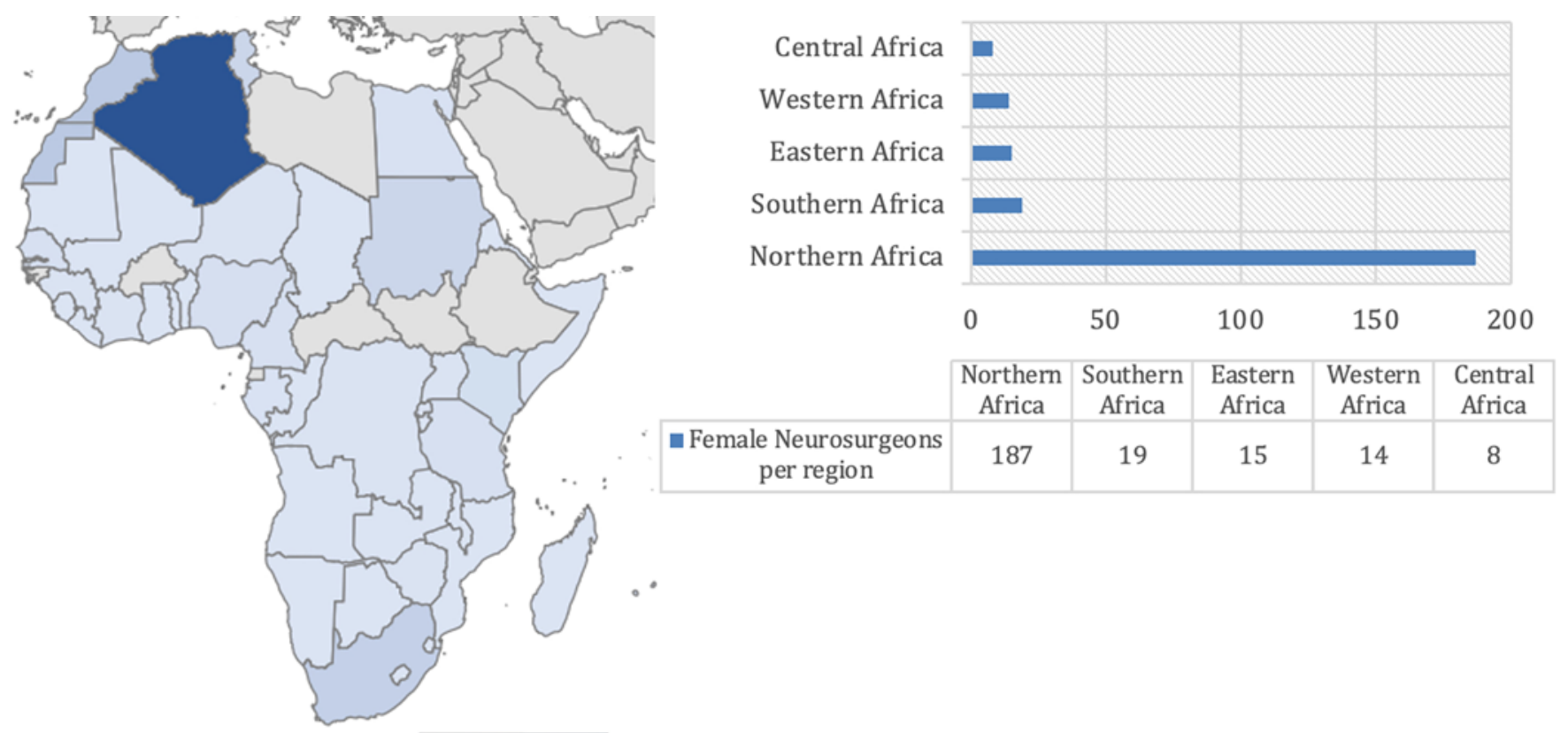

Female Neurosurgeons

FIG. 1. Map of Africa demonstrating the number of qualified female neurosurgeons classified according to regions. 
she continued her training at La Timone in Marseille from 2006 to 2007, then qualified in 2010. She became the first woman associate professor in this discipline in Senegal. Currently, she is the head of the Neurosurgery Department at the General Hospital Idrissa Pouye. Dr. Mame Salimata Diene also holds a leadership position as assistant head of clinical services at the Department of Neurosurgery at Fann Teaching Hospital. Both of these women are among the few who hold leadership positions within academia.

\section{Central Africa}

The region of Central Africa has 9 countries with a population of 180.4 million, but within this region certain countries do not have a single practicing neurosurgeon to date. These countries include Central African Republic, Equatorial Guinea, and São Tomé and Príncipe. In the following countries that currently have no female neurosurgeons, the number of male neurosurgeons are as follows: Chad ( $\mathrm{n}=3)$, Republic of Congo $(\mathrm{n}=5)$, Angola $(\mathrm{n}=14)$.

The DRC is the largest country within the region and has a population of 84.07 million, which is served by 11 qualified neurosurgeons. Dr. Sarah Mutomb, who was trained in Senegal and recently qualified in 2019, is the first and currently only female neurosurgeon in DRC. Cameroon has the highest number of female neurosurgeons in Central Africa, with a total of 5, and Dr. Mirelle Moumi was the first to graduate in 2008 after being trained in Dakar, Senegal. Gabon currently has 2 certified female neurosurgeons.

\section{Eastern Africa}

The Eastern African region comprises 15 countries with a population of 537.9 million. Countries such as Comoros, Djibouti, Eritrea, and Seychelles do not have a single practicing neurosurgeon. In addition, Burundi, Djibouti, Malawi, and Somalia do not have a female neurosurgeon. Kenya leads the region with 6 female neurosurgeons. Dr. Sylvia Shitsama and Dr. Susan Karanja both graduated in 2015 from the University of Nairobi and KwaZulu-Natal, respectively, and became pioneers in Kenya. Four other women joined them to make a total of 6 WIN in Kenya. Two hold lectureship positions: Dr. Tracy John is the secretary of the East African Neurosurgery Society, and Dr. Beverly Cheserem sits on the WFNS Young Neurosurgeons Forum (YNF).

Tanzania follows with 4 female neurosurgeons. Drs. Aingaya Kaale and Happiness Rabiel graduated as neurosurgeons in 2018, followed by 2 additions in 2020. Dr. Constansia Bureta recently became the first female neurosurgeon in this region to complete a PhD from Japan. Dr. Rabiel established a neurosurgical department in Arusha, Tanzania, in 2019.

Ethiopia has 2 qualified neurosurgeons, the first being Dr. Yordanos Ashagre (2015). Dr. Juliet Sekabunga is the first female neurosurgeon to graduate from Uganda, and she continued her studies and completed her pediatric fellowship at Toronto's Hospital for Sick Children (SickKids). Dr. Claire Karekezi graduated from the WFNS Rabat Training Center, 7,8 Morocco, in 2016 and became the first female neurosurgeon in Rwanda. She completed a neuro-oncology and skull base surgery fellowship at the
University of Toronto, Toronto Western Hospital, in June 2018, before establishing a new neurosurgical unit at the Rwanda Military Hospital. She also holds several leadership positions, including being the first chair of the AWIN Committee of the CAANS, a representative of WFNS Global Neurosurgery, and a committee member of WFNS YNF.

\section{Southern Africa}

Southern Africa is located on the southernmost tip of the continent. It comprises the following 8 countries: Botswana, Lesotho, Mozambique, Namibia, RSA, Swaziland, Zambia, and Zimbabwe. The history of female neurosurgeons within this region started in the early 1990s. Since then, the numbers have grown within this male-dominated specialty. The first female neurosurgeon to qualify in this region was Dr. Minette du Preez, who trained at the University of the Free State. Although initially hesitant to enter the training program because there were no other women in the department, she pressed on after one of her professors encouraged her by mentioning that women all over the world were practicing within the discipline, and she registered as a specialist neurosurgeon in 1994. Shortly thereafter, her Zimbabwean-born colleague Dr. Nozipho Maraire qualified as a neurosurgeon from the Yale School of Medicine. She proceeded to be a trailblazer within the field by completing her subspecialty training in pediatric neurosurgery at the Beth Israel Hospital in New York. Until recently, she was the only woman from this region who had pursued subspeciality training. These women laid a solid foundation for the next generation of Southern Africa's women to thrive in this discipline and continue their legacy.

Within Southern Africa, the RSA has the highest number of registered female neurosurgeons, a total of 14, and added to this number are 4 women who have just passed their examination, taking the number to 18 . The RSA is currently ranked third on the continent when it comes to the number of female neurosurgeons, with $7.4 \%$ of AWIN, after Algeria and Morocco. This figure is consistent with other middle-income countries, such as Brazil (5.5\%), and higher than in other countries, like India $(<2.5 \%),{ }^{9,10}$ Five female surgeons are full-time academic staff, the largest number $(n=3)$ being at the University of Cape Town. With regard to leadership positions, Dr. Coceka Mfundisi became the first woman to qualify as a neurosurgeon from the University of Pretoria in its 100-year history. Today she works as a specialist neurosurgeon at Life Brenthurst and Busamed in Modderfontein, and at Chris Hani Baragwanath Hospital, and she holds a position in the WFNS Global Neurosurgery Committee. Dr. Nqobile Thango, who recently completed her fellowship in pediatric neurosurgery at the Red Cross Children's Hospital in December 2020, is a committee member of the WFNS YNF, along with the Young African Neurosurgeons Forum education committee.

\section{Discussion}

Challenges of Becoming a Neurosurgeon in Africa for Female Candidates

Culture, especially in the African context, remains the 


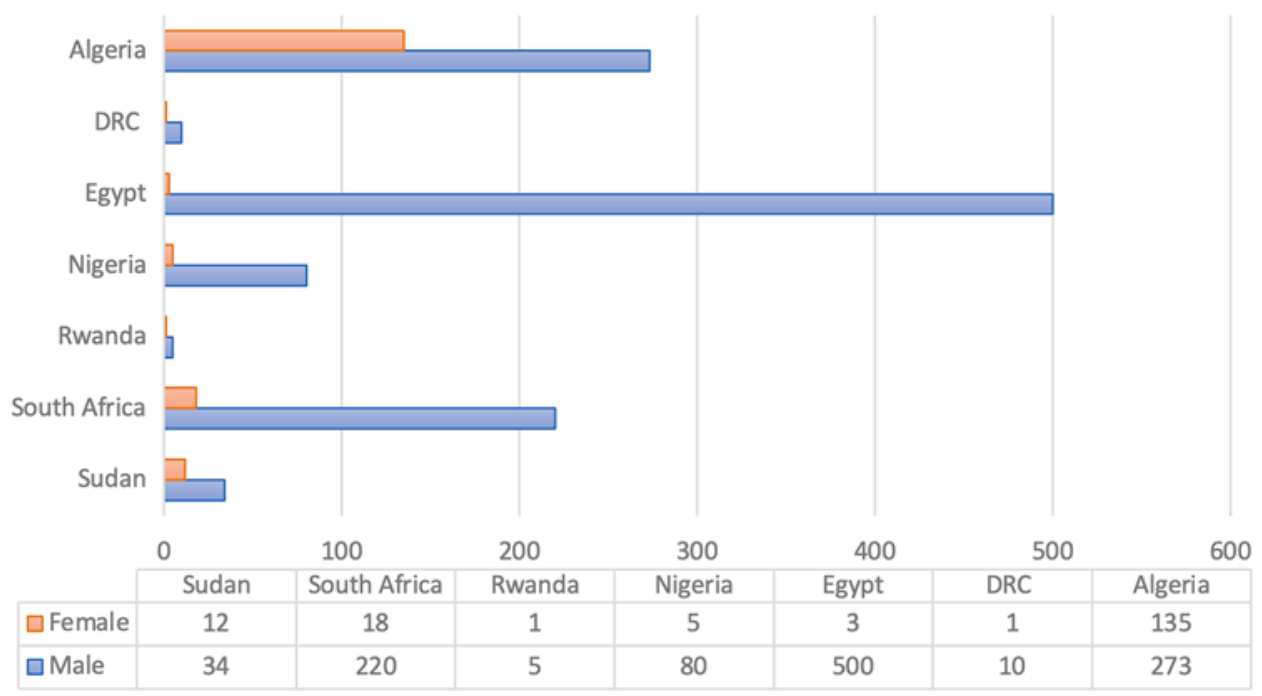

FIG. 2. Bar graph comparing the number of male and female neurosurgeons in selected African countries.

first barrier faced by women choosing any medical field..$^{9,11}$ In some areas it is still common that decisions are made by male heads of households or male local chiefs and leaders; hard science like medicine, and in this case neurosurgery, is still feared by women, and this could explain why women are still underrepresented in neurosurgery in some areas of the sub-Saharan African countries. The road to becoming a successful neurosurgeon is long, with many barriers for any candidate from any country to overcome. Neurosurgeons in general must adhere to a busy work schedule, being on call to respond to emergencies at night, on weekends, and even sometimes during holidays, and the time required to become a full, well-trained neurosurgeon is long., ${ }^{1,12}$ That may be challenging for women trying to balance a career with family obligations; the stereotypical role that has been cast on women in the African context is the belief that they want time to have children and raise them without being busy at the hospital. Due to the African societal view that the role of a woman is to look after the house, bring up children, and cater to her husband's needs, many women today are still expected to conform to these standards. ${ }^{13,14}$

\section{Training}

Traditionally medicine has been a male-dominated field, but as we entered the 21 st century a shift was apparent. Women now make up more than $50 \%$ of medical school graduates..$^{15,16}$ Regarding the numbers closer to home in Sudan, women account for 70\%-80\% of trainees enrolled in their undergraduate medical training programs. ${ }^{17}$ Unfortunately, these numbers are not mirrored within surgical disciplines, and women remain underrepresented. Neurosurgery is counted among the surgical disciplines with the least gender parity-the increase in the number of females lags behind other specialties, like general surgery (Fig. 2). In 2008, Women in Neurosurgery published a landmark paper, which painted a grim picture of the status quo of women in the field and alerted the neurosurgical community to the importance of addressing gender inequity and confirmed that gender imbalance ex- ists within the discipline. ${ }^{18}$ The number of women entering training and practicing as neurosurgeons was not increasing, and the article shed light on the obstacles in the recruitment and retention of women and offered useful suggestions on how this critical matter should be addressed. Counted among the most recognized barriers that prevent women from entering surgical training is a lack of female mentors and a perceived hostile culture toward women..$^{13,19}$

The example of women leaders in Africa inspired many young residents (Fig. 3) to pursue their dream career; for instance, Professor El Abbadi's leadership inspired younger generations to follow her footsteps. This great leadership is reflected by the proportion of female residents, which is estimated at $40 \%$ in Morocco. She also was a continental mentor to Dr. Claire Karekezi and Dr. Diawara Selyan, who both became female leaders in their respective countries. Algeria and Senegal have done the same, inspiring and mentoring several women from different countries.

Another great example of female collaboration and leadership is represented by the creation of the Mediterranean Association of Neurological Surgeons (MANS) by Professor El Abbadi in 2014. She gathered neurosurgeons from two continents to create this regional society, creating a bridge between Europe and Africa and facilitating scientific exchanges. The Mediterranean Association of Neurological Surgeons was the first neurosurgical society to elect women as its first two presidents: Professor El Abbadi and Professor Bakhti. These two leaders collaborated on the WFNS Women in Neurosurgery Committee. They created an open and safe environment where female neurosurgeons from developing countries could discuss social and professional issues, get in touch, and feel supported, by systematically organizing WIN meetings in every neurosurgical meeting (Fig. 4). In 2017, the WFNS Women in Neurosurgery Committee organized its first female scientific session at the World Congress in Istanbul, Turkey. It was followed by numerous female scientific sessions in which male neurosurgeons were invited to moderate and work as peers toward the greater representation of AWIN. 


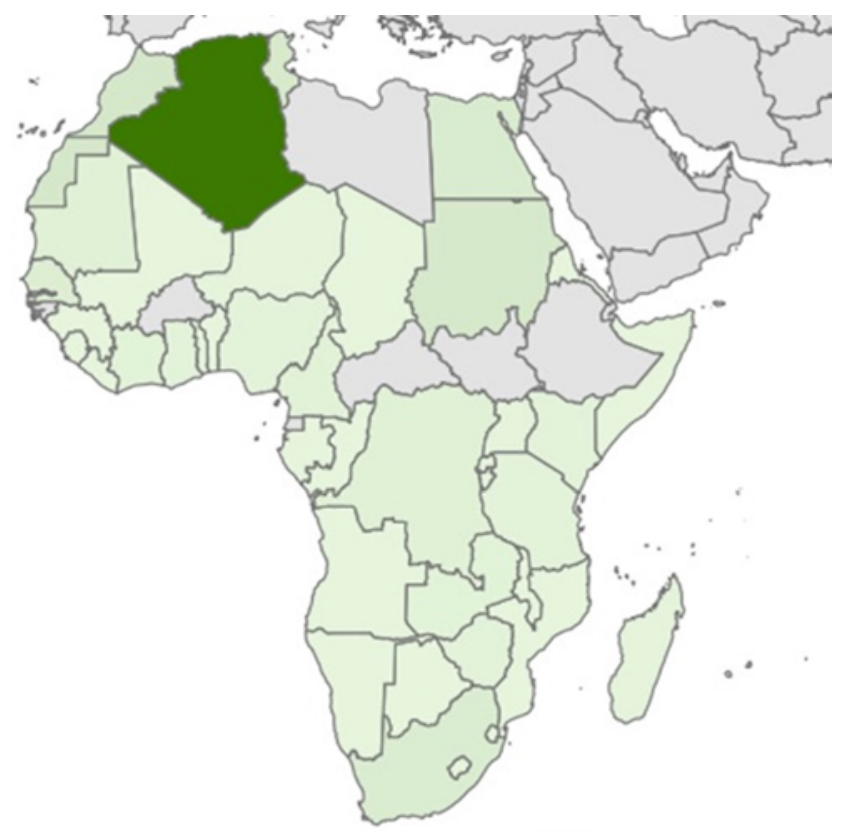

Neurosurgical Residents

0

FIG. 3. Map depicting the number of female neurosurgical residents within Africa.

\section{Academic Representation}

Across all medical disciplines an increase in the representation of women in academia and leadership structures can be appreciated. Women make up $22 \%$ of full professors, $18 \%$ of departmental chairs, and only $17 \%$ of medical school deans according to the Association of American Medical Colleges. ${ }^{15,20}$ Within neurosurgery these numbers rapidly decline, with only $4 \%$ of women holding full professorships, the second lowest after ortho- pedic surgery. ${ }^{16}$ Taking it closer to home, on the continent only $3 \%$ of AWIN have a full professorship (Table 1), and all are found within Northern Africa-as previously mentioned, this region has the highest number of practicing female neurosurgeons. Representation of women in academia creates a pipeline effect, where women are attracted into neurosurgery and have mentors who provide support that retains and harnesses the potential of future surgeons.

\section{Future Directions}

Although great strides have been made in achieving a gender balance on the continent over the past decades, barriers for recruiting and retaining WIN are still enormous. ${ }^{13,19-21}$ Women neurosurgeons are still underrepresented in leadership positions and academic neurosurgery. We are working hard to increase representation but also to increase mentorship to the younger women. Recently, the first WhatsApp group of AWIN was created, and through this platform we discuss various subjects and share papers and books, as well as conference opportunities, and we are also having more scientific WIN sessions during our major neurosurgical conferences (Fig. 5). The WhatsApp group allowed us to reach out to different women and to initiate this project after establishing a complete database of all WIN in Africa. We hope to build up mentorship and networking programs to help one another advance in our demanding neurosurgical careers.

\section{Conclusions}

The general status of a woman is changing in several parts of Africa. Many governments are now committed to providing equal education for girls; women are taking charge of several responsibilities in many nations at both national and international levels; there is an increasing number of women in the health sector; and women are now choosing medical careers and being represented in

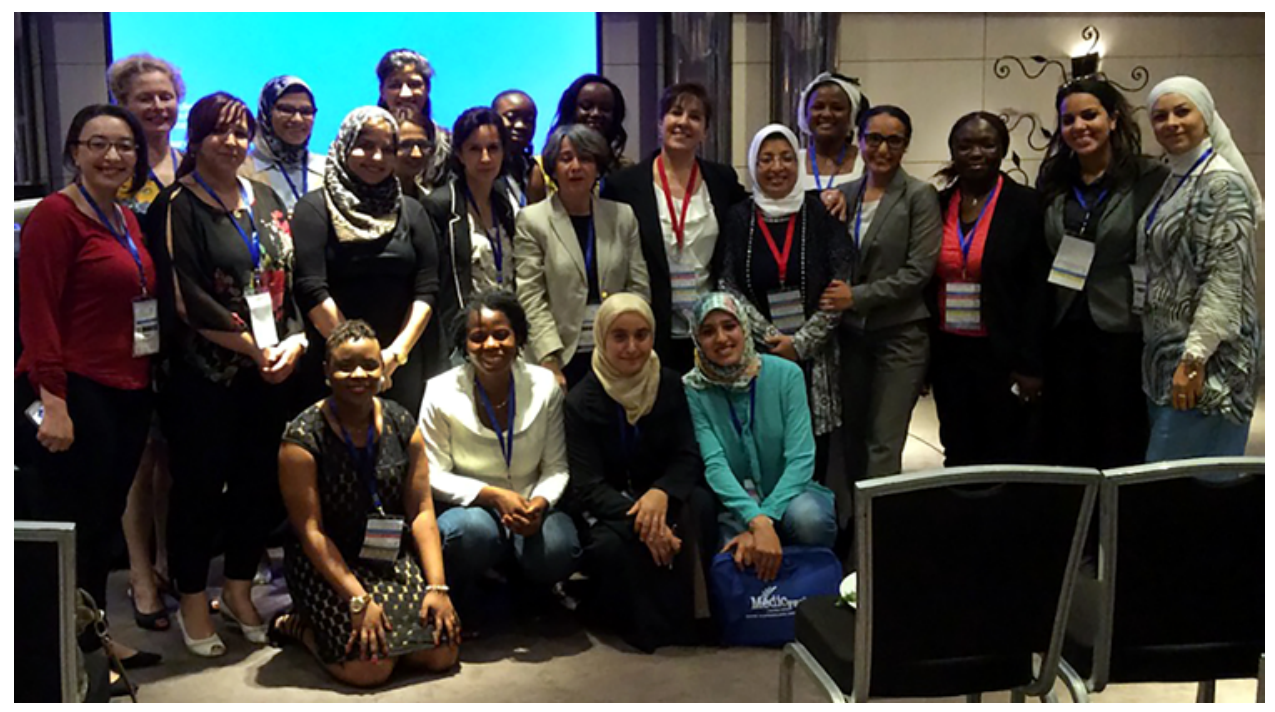

FIG. 4. WFNS Women in Neurosurgery at the 24th Annual Moroccan Congress of Neurosurgery combined with the 65th Congress of the French-Speaking Society of Neurosurgery, May 2015, Casablanca, Morocco. 


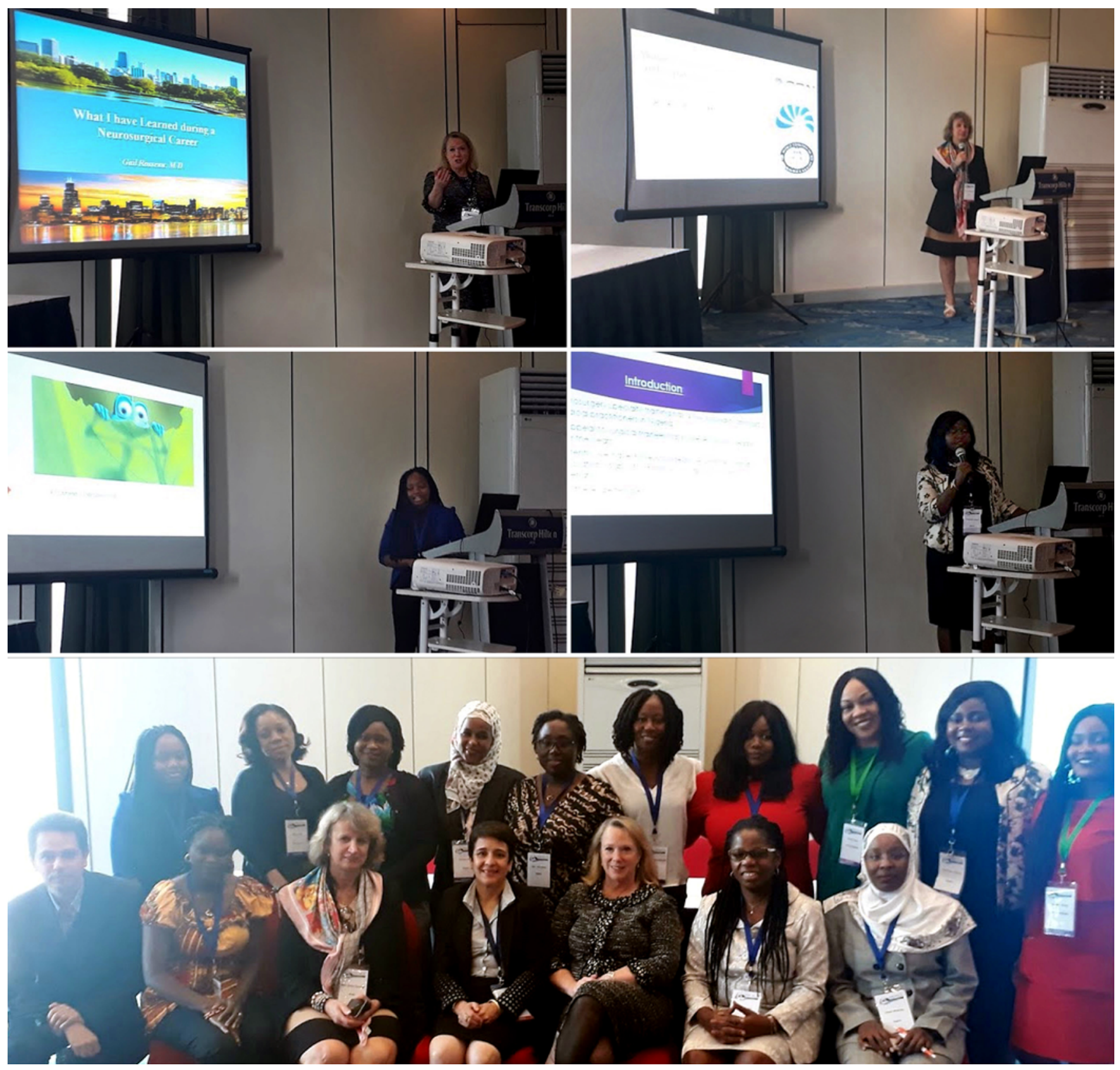

FIG. 5. AWIN in Abuja, Nigeria, during the 2018 CAANS Congress, July 2018.

surgical fields. This shows that societies are changing as African women are increasingly able to choose their own course of life.

Even though a lot has been achieved, the paucity of WIN persists despite the increase in the number of female medical doctors on the continent. We are happy with the progress made, but it is clear that there is still a lot to do. There is a need for more experienced female neurosurgeons to help other young women to overcome different challenges in our demanding field and to promote their accomplishments through mentorship and guidance. To make it in neurosurgery, which is a male-dominated field, it takes a lot of hard work, dedication, and passion. Being a woman in neurosurgery should be an inspiration rather than a barrier.

\section{Acknowledgments}

We express our sincere gratitude to all AWIN because of their courageous efforts, along with the continual effort of aiming for excellence and mentoring the next generation. The future of AWIN indeed rests on the shoulders of great giants.

\section{References}

1. Spetzler RF. Progress of women in neurosurgery. Asian J Neurosurg. 2011;6(1):6-12. 
2. El Khamlichi A. African neurosurgery part II: current state and future prospects. Surg Neurol. 1998;49(3):342-347.

3. Dewan MC, Rattani A, Fieggen G, et al. Global neurosurgery: the current capacity and deficit in the provision of essential neurosurgical care. J Neurosurg. 2018;130(4):1055-1064.

4. Women in Neurosurgery. Committee activities. WFNS. Accessed January 20, 2021. https://sites.google.com/site/womeninneurosurgery/home

5. Carson BS. E. Latunde Odeku: the first African-American neurosurgeon trained in the United States-commentary. Neurosurgery. 2007;60(4):769-772.

6. Odeku EL. Beginnings of neurosurgery at the University of Ibadan, Nigeria. Ann Ib Postgrad Med. 2007;5(2):34-43.

7. Karekezi C, El Khamlichi A. Takeoff of African neurosurgery and the World Federation of Neurosurgical Societies Rabat Training Center alumni. World Neurosurg. 2019;126: 576-580.

8. Karekezi C, El Khamlichi A, El Ouahabi A, et al. The impact of African-trained neurosurgeons on sub-Saharan Africa. Neurosurg Focus. 2020;48(3):E4.

9. Zanon N. Women in neurosurgery: a challenge to change history-Brazil, São Paulo. Childs Nerv Syst. 2011;27(3): 337-340.

10. Palanisamy D, Battacharjee $\mathrm{S}$. What it is to be a woman neurosurgeon in India: a survey. Asian J Neurosurg. 2019;14(3): 808-814.

11. Cassell J. Doing gender, doing surgery: women surgeons in a man's profession. Hum Organ. 1997;56(1):47-52.

12. Corley J, Kim E, Philips CA, et al. One hundred years of neurosurgery: contributions of American women. J Neurosurg. 2021;134(2):337-342.

13. Park J, Minor S, Taylor RA, et al. Why are women deterred from general surgery training? Am J Surg. 2005;190(1): 141-146.

14. Phillips EA, Nimeh T, Braga J, Lerner LB. Does a surgical career affect a woman's childbearing and fertility? A report on pregnancy and fertility trends among female surgeons. $J$ Am Coll Surg. 2014;219(5):944-950.

15. Abosch A, Rutka JT. Women in neurosurgery: inequality redux. J Neurosurg. 2018;129(2):277-281.
16. Renfrow JJ, Rodriguez A, Wilson TA, et al. Tracking career paths of women in neurosurgery. Neurosurgery. 2018;82(4): $576-582$.

17. Elhag MM, Abdelmawla MA. Gender-based assessment of science, technology and innovations ecosystem in the Sudan. Afr J Rural Dev. 2020;5(1):97-113.

18. Benzil DL, Abosch A, Germano I, et al. The future of neurosurgery: a white paper on the recruitment and retention of women in neurosurgery. J Neurosurg. 2008;109(3):378-386.

19. Marks IH, Diaz A, Keem M, et al. Barriers to women entering surgical careers: a global study into medical student perceptions. World J Surg. 2020;44(1):37-44.

20. Lewiss RE, Silver JK, Bernstein CA, et al. Is academic medicine making mid-career women physicians invisible? J Womens Health (Larchmt). 2020;29(2):187-192.

21. Wall SL, Troisi K. Impact of gender bias on women surgeons: a South African perspective. J Med Ethics. 2020;46(11): $785-786$

\section{Disclosures}

The authors report no conflict of interest concerning the materials or methods used in this study or the findings specified in this paper.

\section{Author Contributions}

Conception and design: Karekezi, Thango. Acquisition of data: Karekezi, Aliu-Ibrahim, Bechri, Broalet, Bougrine, Cheserem, Mbaye, Shabhay, Tighilt. Drafting the article: Karekezi, Thango. Critically revising the article: Karekezi, Thango, Cheserem. Reviewed submitted version of manuscript: all authors. Approved the final version of the manuscript on behalf of all authors: Karekezi. Study supervision: Karekezi, Bakhti, El Abbadi.

\section{Correspondence}

Claire Karekezi: Rwanda Military Hospital, Kicukiro District, Kigali, Rwanda. clairekarekezi@gmail.com. 